\title{
Preparation and Characterization of Sulfated Zirconia from a Commercial Zirconia Nanopowder
}

\author{
LATIFAH HAULI', KARNA WIJAYA ${ }^{1 *}$ and RIA ARMUNANTO ${ }^{1}$ \\ 'Department of Chemistry, Faculty of Mathematics and Natural Sciences, \\ Universitas Gadjah Mada, Sekip Utara Bulaksumur, Yogyakarta, 55281, Indonesia. \\ *Corresponding author E-mail: karnawijaya@ugm.ac.id \\ http://dx.doi.org/10.13005/ojc/340348
}

(Received: March 13, 2018; Accepted: March 31, 2018)

\begin{abstract}
Sulfated zirconia (SZ) catalysts were prepared by impregnation from commercial zirconia nanopowder with different concentrations of sulfuric acid $(0.2,0.5$, and $0.8 \mathrm{M})$ and calcination temperatures $\left(600,700,800\right.$, and $\left.900^{\circ} \mathrm{C}\right)$. SZ catalysts were characterized by Fourier transform infrared spectroscopy (FTIR), X-ray diffraction (XRD), Transmission electron microscopy (TEM), Surface area analyzer (SAA), and acidity test by ammonia adsorption. FTIR showed that the modification of zirconia with sulfuric acid enhanced the catalysts acid sites which confirmed by acidity test and it also showed the $0.8 \mathrm{M} \mathrm{SZ}$ at $600^{\circ} \mathrm{C}$ was the optimal condition with the highest acidity value of $3.81 \mathrm{mmol} / \mathrm{g}$. XRD showed that SZ crystalline structure was in a monoclinic phase and the intensity decreased with increasing concentration and decreasing calcination temperature.
\end{abstract}

Keywords: Zirconia, Sulfated zirconia, Catalyst, Solid acid catalyst.

\section{INTRODUCTION}

The recent widely developed heterogeneous catalyst is catalysts which had a group of metal oxides such as zirconia $\left(\mathrm{ZrO}_{2}\right)$. It has corrosionresistant properties, strong chemical resistance, low thermal conductivity, not conduct electricity, and better thermal power than alumina ${ }^{1}$. This material also has so potential in many applications such as hydrolysis, biodiesel production, pillared material, and often used for hydrocracking process ${ }^{2-4}$. It was developed and used as a catalyst because it had double characteristics as a weak acid and base catalyst depend on the treatment process, so that is possible to be used in many catalytic reaction ${ }^{4}$. $\mathrm{ZrO}_{2}$ catalyst could be used as an acid catalyst by modification process using acidic compounds such as sulfuric acid ${ }^{5}$. The sulfated zirconia (SZ) material which obtained by modification process would produce a high acidic catalyst because of the formation many active sites of Brønsted and Lewis acid sites in the structure ${ }^{6}$. Among many super acid solids, SZ is the most studied material because of its ability to catalyze with its higher acidity than other inorganic acids.

This is an Open Access article licensed under a Creative Commons Attribution-Non Commercial-Share Alike 4.0 International License (https://creativecommons.org/licenses/by-nc-sa/4.0/), which permits unrestricted Non Commercial use, distribution and reproduction in any medium, provided the original work is properly cited. 
The catalytic properties of SZ catalyst depend on treatment methods, $\mathrm{ZrO}_{2}$ precursor, calcination temperature, sulfating agent, etc ${ }^{7}$. Preparation of SZ catalyst could be done by various methods such as hydrothermal ${ }^{8}$ and sol gel methods ${ }^{9}$. However, it has advantages and disadvantages to produce a good catalyst. In this study, $\mathrm{ZrO}_{2}$ was chosen as catalyst because of its good material properties and characteristics. Preparation of SZ catalyst was done by wet impregnation method from commercial $\mathrm{ZrO}_{2}$ nanopowder and using sulfuric acid as sulfating agent. The different concentrations and calcination temperatures were investigated in this study in order to know the effect of its on SZ catalyst.

\section{EXPERIMENTAL}

\section{Materials}

The materials used in this study were commercial zirconia nanopowder $\left(\mathrm{ZrO}_{2} 60-70 \mathrm{~nm}\right)$ from China (purity 99\%), sulfuric acid (98\%) from Merck, and ammonia (25\%) from Merck.

\section{Sample preparation}

Sulfated Zirconia (SZ) catalysts were prepared from $10 \mathrm{~g}$ of $\mathrm{ZrO}_{2}$ nanopowder added into $150 \mathrm{~mL} \mathrm{H}_{2} \mathrm{SO}_{4}$ with different concentrations $(0.2,0.5$, and $0.8 \mathrm{M})$ respectively, then stirred for 24 hours. The different concentrations were performed to determine the effect of sulfuric acid concentration on zirconia. SZ catalysts were then dried in an oven at $100{ }^{\circ} \mathrm{C}$ for overnight, calcined with different temperatures $(600,700,800$, and $900{ }^{\circ} \mathrm{C}$ ) for 4 hour. After that SZ catalysts were crushed and sieved in a 250 mesh sieve. The different temperatures were conducted to learn the effect on SZ catalyst.

The acidity test of SZ was determined with ammonia adsorption by gravimetric method. The acidity value of $\mathrm{ZrO}_{2}$ nanopowder and sulfated ziconia were calculated by using the equation:

$$
\text { Acidity value }=\frac{\text { weight of sample after adsorption }- \text { weight of sample before adsorption }}{\text { weight of sample before adsorption } \mathrm{x} \text { Mr ammonia }}
$$

\section{Sample characterization}

The SZ catalysts were characterized by Fourier transform infrared spectroscopy (FTIR, Shimadzu Prestige-21) in range $4000-500 \mathrm{~cm}^{-1}$ with a $\mathrm{KBr}$ disc technique. The presence of sulfate groups on $\mathrm{ZrO}_{2}$ was confirmed by FTIR. X-ray diffraction (XRD, Shimadzu XRD 6000) with $\mathrm{Cu} \mathrm{K}$ radiation at $40 \mathrm{kV}$ and $40 \mathrm{~mA}$ under space conditions. Crystallite size was determined using Scherrer formula with a shape factor $(K)$ of $0.89: D=(0.9 \lambda) / b \cos \theta$, where $D$ is the crystallite size $(\mathrm{nm}), \lambda$ is the radiation wavelength $(0.154056 \mathrm{~nm}), \theta$ is the diffraction peak angle and $b$ is the corrected half-width at halfmaximum intensity (FWHM). Transmission electron microscopy (TEM, Hitachi H8100A) at 100 $\mathrm{kV}$ for confirming catalyst morphology. Surface area analyzer (SAA, Quantachrome NovaWin Series version 11.0). Sample was thoroughly outgassed for $4 \mathrm{~h}$, at $200{ }^{\circ} \mathrm{C}$, bath temp. of $77.3 \mathrm{~K}$, and equil time of $60 / 60 \mathrm{sec}$ (ads/des) then the weight of the outgassed sample was that used in calculations. The specific surface area was calculated by applying the Brunauer-Emmett-Teller (BET) method.

\section{RESULTS AND DISCUSSION}

\section{FTIR characterization}

FTIR analysis showed the absorption band at $490-745 \mathrm{~cm}^{-1}$ were corresponded by the presence of $\mathrm{Zr}-\mathrm{O}-\mathrm{Zr}$ bond ${ }^{10}$. The absorption band at $3400-3800 \mathrm{~cm}^{-1}$ showed the streching vibration of the $\mathrm{O}-\mathrm{H}$ bond and the absorption band around at $1636 \mathrm{~cm}^{-1}$ corresponded to bending vibration of $\mathrm{O}-\mathrm{H}$ bond ${ }^{11}$. The spesific absorption band of $\mathrm{SZ}$ catalyst at $1120-1224 \mathrm{~cm}^{-1}$ characterized to symmetric streching vibration of $\mathrm{SO}_{4}{ }^{2-}$ bidentat species ${ }^{12}$. This observation also indicated the presence of covalent $S=O$ double bonds on surface sulfate groups at SZ which could effect the acidity of catalyst ${ }^{13}$. In Fig. 1 showed $\mathrm{SZ}$ of $0.2 \mathrm{M}$ and calcined at different temperatures did not clearly show the specific peak of sulfate groups. It was different from SZ of $0.5 \mathrm{M}$ at $600{ }^{\circ} \mathrm{C}$ (Fig. 2), it had showed the spesific peak of sulfate groups. SZ of $0.8 \mathrm{M}$ at $600^{\circ} \mathrm{C}$ (Fig. 3) had the stronger sulfate groups specific peak than others. It showed that sulfate groups had impregnated on $\mathrm{ZrO}_{2}$ well. However overall in this concentration variations, the peak of $\mathrm{SO}_{4}{ }^{2-}$ would appear at the higher concentration and disappear at higher calcination temperature. Sulfate groups of SZ had the important role in catalytic activity because it need the high acidity of catalyst reaction ${ }^{14}$. The higher acidity would have an effect on the good catalytic reaction. 


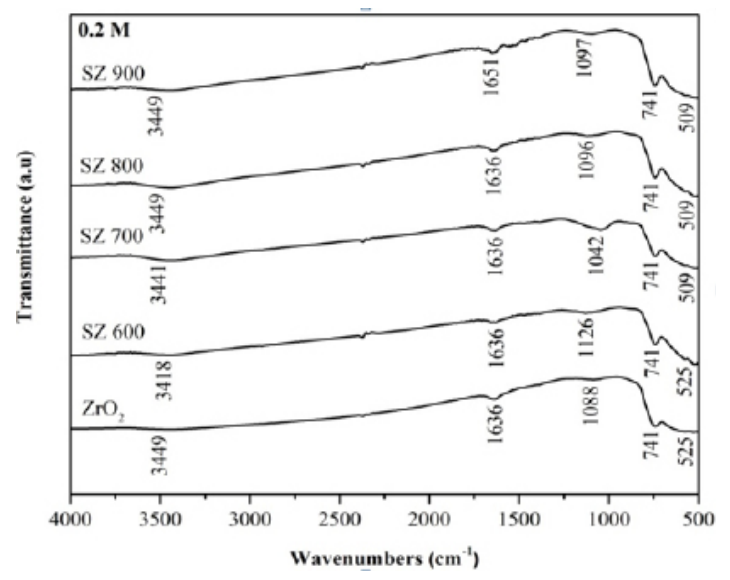

Fig. 1. FTIR spectra of $0.2 \mathrm{M} \mathrm{SZ}$

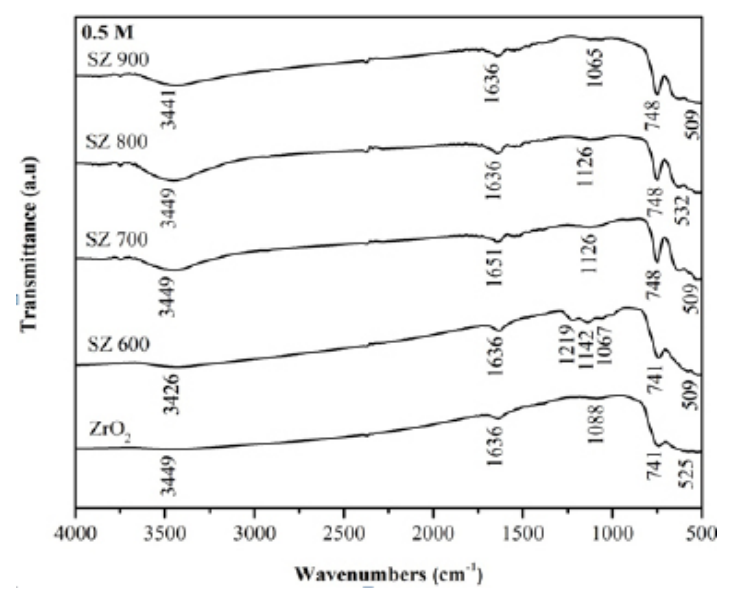

Fig. 2. FTIR spectra of $0.5 \mathrm{M} \mathrm{SZ}$

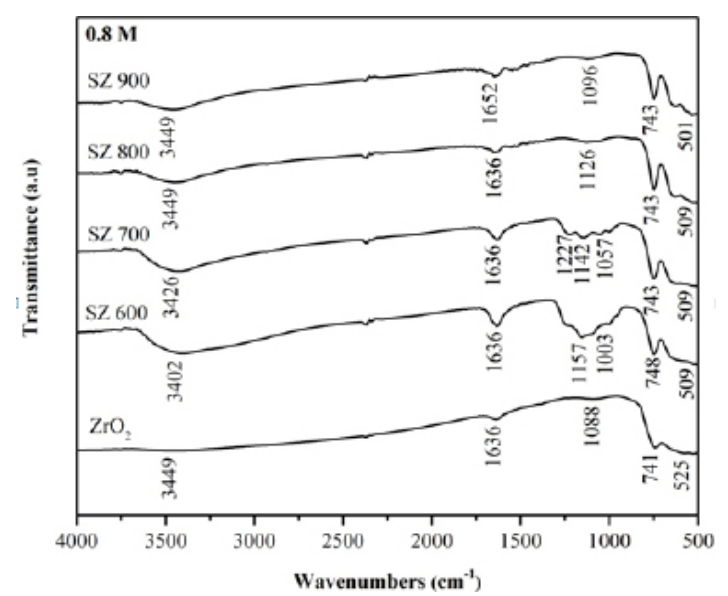

Fig. 3. FTIR spectra of $0.8 \mathrm{M} \mathrm{SZ}$

\section{Acidity test}

FTIR analysis of ammonia adsorption on solid surface could distinguish both the Brønsted acid sites and Lewis acid sites. Adsorption band at $1404 \mathrm{~cm}^{-1}$ was associated with $\mathrm{NH}_{3}$ adsorption on the Brønsted acid sites ${ }^{15,16}$. Adsorption band around at $1119 \mathrm{~cm}^{-1}$ was associated with $\mathrm{NH}_{3}$ adsorption on the Lewis acid sites ${ }^{17}$. In this study, acidity value for $\mathrm{ZrO}_{2}$ of $0.059 \mathrm{mmol} / \mathrm{g}$ and $\mathrm{SZ}$ of $0.8 \mathrm{M}$ at $600{ }^{\circ} \mathrm{C}$ had the highest acidity as shown the acidity value in Table 1 as confirmed in Fig. 6 from FTIR observation which had the stronger peak of $\mathrm{NH}_{3}$ adsorption than others (Fig. 4 and Fig. 5). The catalytic acidity would decrease at the higher calcination temperature and increase at the higher concentration. It was caused by sulfate groups loading on SZ catalysts which lost because of the higher calcination temperature. Modification of $\mathrm{ZrO}_{2}$ with sulfuric acid could enhance the acid strengh because of two factors i.e. the Brønsted acid sites from bridging $\mathrm{Zr}-\mathrm{OH}$ groups and the Lewis acid sites from low cordinate $\mathrm{Zr}$ ions ${ }^{18}$. It caused the SZ catalysts had the high acidity.

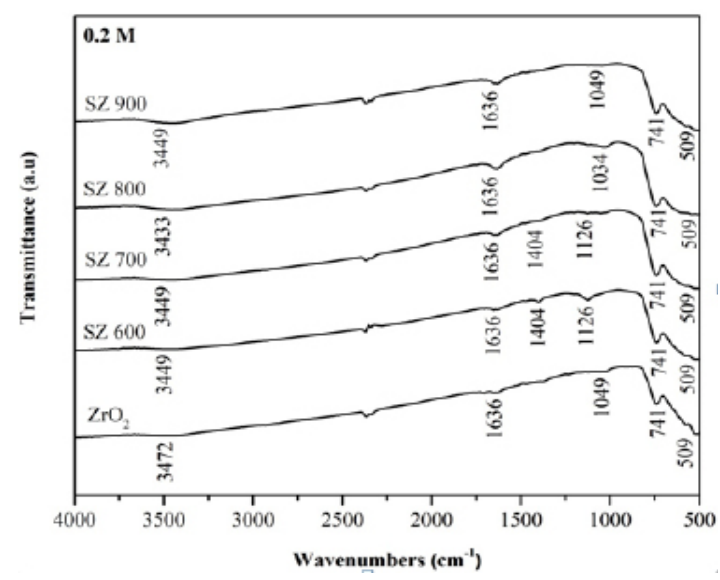

Fig. 4. $\mathrm{NH}_{3}$-FTIR spectra of $0.2 \mathrm{M} \mathrm{SZ}$

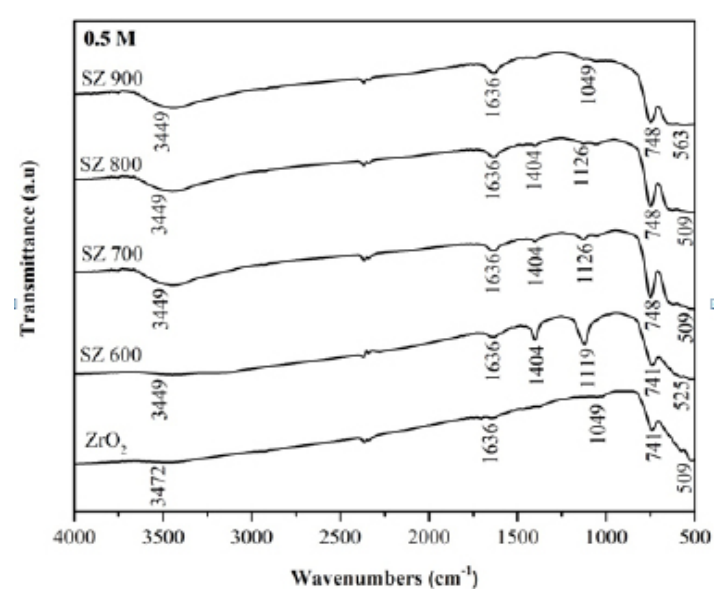

Fig. 5. $\mathrm{NH}_{3}$-FTIR spectra of $0.5 \mathrm{M} \mathrm{SZ}$ 


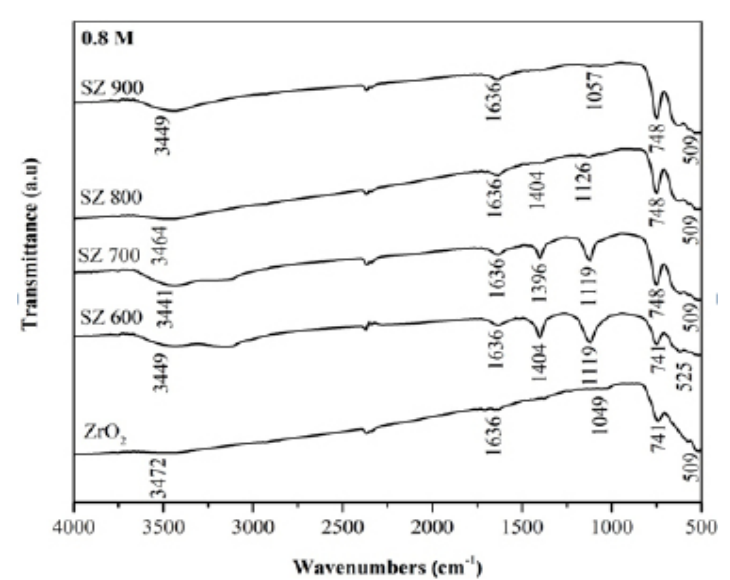

Fig. 6. $\mathrm{NH}_{3}-\mathrm{FTIR}$ spectra of $0.8 \mathrm{M} \mathrm{SZ}$

Table 1: Acidity value of sulfated zirconia (SZ)

\begin{tabular}{lcccc}
\hline Sample & \multicolumn{5}{c}{ Acidity value (mmol/g) } \\
\hline & $600{ }^{\circ} \mathrm{C}$ & $700^{\circ} \mathrm{C}$ & $800^{\circ} \mathrm{C}$ & $900^{\circ} \mathrm{C}$ \\
$0.2 \mathrm{M} \mathrm{SZ}$ & 0.47 & 0.23 & 0.12 & 0.06 \\
$0.5 \mathrm{M} \mathrm{SZ}$ & 0.94 & 0.59 & 0.41 & 0.29 \\
$0.8 \mathrm{M} \mathrm{SZ}$ & 3.81 & 1.47 & 0.71 & 0.12 \\
\hline
\end{tabular}

\section{XRD characterization}

XRD analysis of $\mathrm{ZrO}_{2}$ nanopowder and $\mathrm{SZ}$ catalysts at different calcination temperatures and concentrations were presented in Fig. 7, Fig. 8, and Fig. 9. In this study overall the intensity of SZ catalysts increased with the increasing calcination temperature. It was due to lost sulfate groups loading which impregnated on $\mathrm{ZrO}_{2}$ nanopowder. At the different concentrations, intensity of SZ catallysts decreased with the increasing concentration. It caused the sulfate groups loading on $\mathrm{ZrO}_{2}$ at higher concentration as confirmed by FTIR. XRD analysis also showed the diffraction peak in crystal at $2 \theta=24.7^{\circ}, 27.5^{\circ}, 31.0^{\circ}, 49.2^{\circ}$ were corresponded to monoclinic phase based on data JCPDS 88-2390. This experiment was conducted in order to know the effect of phase change on calcination temperature. But overall this study of $\mathrm{SZ}$ catalysts were in the monoclinic phase. $\mathrm{ZrO}_{2}$ had three phases of crystal structure i.e monoclinic phase under $1140{ }^{\circ} \mathrm{C}$, tetragonal phase at $1140-2370{ }^{\circ} \mathrm{C}$, and cubic phase above $2370{ }^{\circ} \mathrm{C}^{19}$. Ejtemae et al., ${ }^{20}$ had reported the synthesis of SZ nanopowders with sol gel method and it found that tetragonal phase at $500{ }^{\circ} \mathrm{C}$ and was stabled at the higher temperature. However, all of the SZ synthesis process depend on the $\mathrm{ZrO}$ precusor to obtain the stable and active catalyst. The crystal sizes of SZ catalysts were calculated by using Scherrer equation and crystal size for $\mathrm{ZrO}_{2}$ and $\mathrm{SZ}$ were presented in Table 2. The results showed overall the crystallite size decreased with the addition of sulfate. However, the calculation depend on halfmaximum intensity of crystal peak.

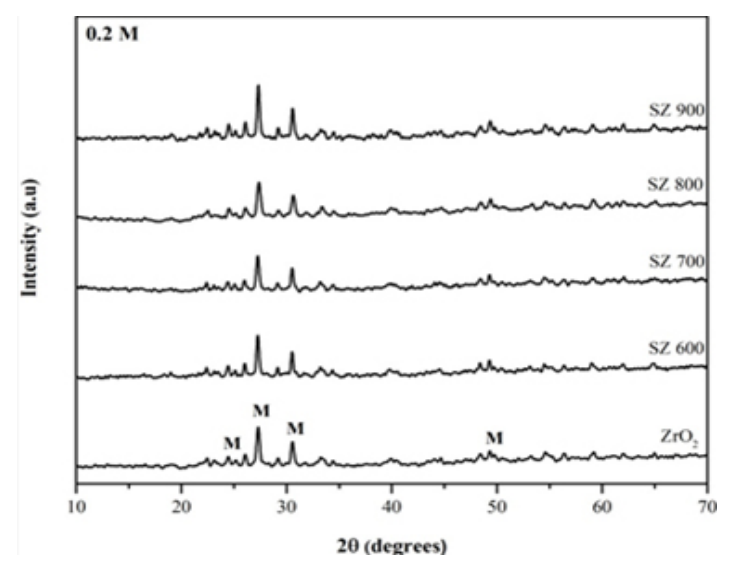

Fig. 7. XRD patterns of $0.2 \mathrm{M} \mathrm{SZ}$

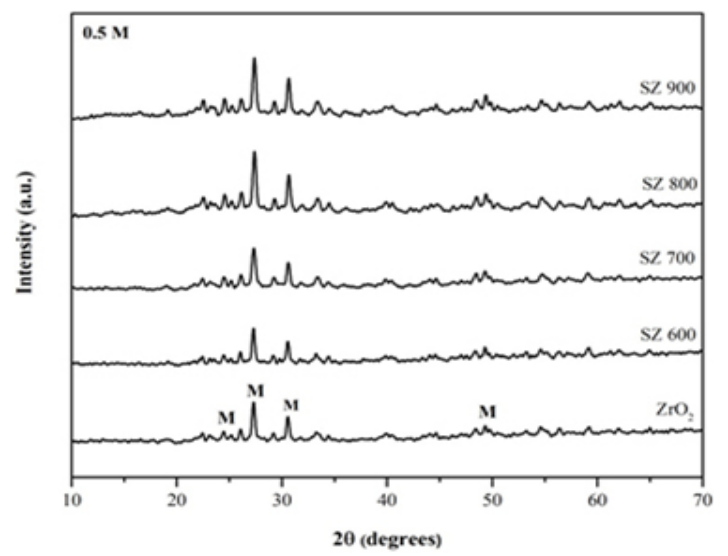

Fig. 8. XRD patterns of $0.5 \mathrm{M} \mathrm{SZ}$

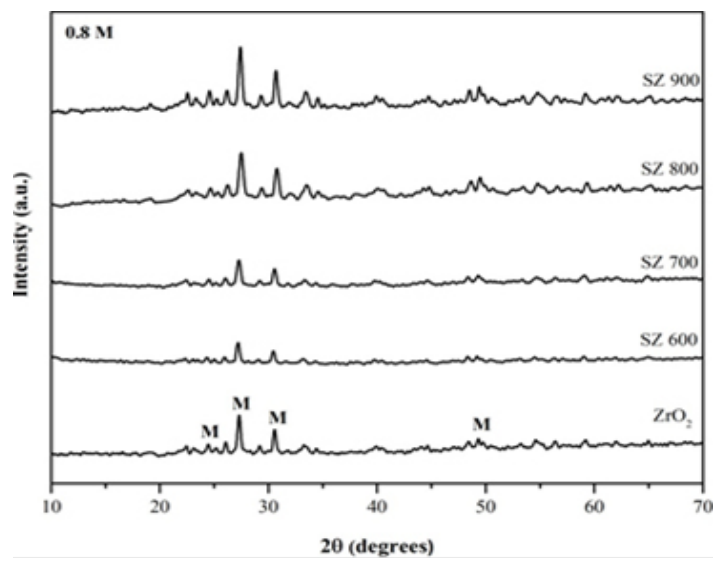

Fig. 9. XRD patterns of $0.8 \mathrm{M} \mathrm{SZ}$ 
Table 2: Data of $\mathrm{ZrO}_{2}$ and SZ

\begin{tabular}{lcc}
\hline Sample & Crystallite size $(\mathrm{nm})$ & SBET $\left(\mathrm{m}^{2} \mathrm{~g}^{-1}\right)$ \\
\hline $\mathrm{ZrO}_{2}$ & 27.32 & 12,27 \\
$0.2 \mathrm{M} \mathrm{SZ} \mathrm{600}$ & 33.84 & - \\
$0.2 \mathrm{M} \mathrm{SZ} \mathrm{700}$ & 32.74 & - \\
$0.2 \mathrm{M} \mathrm{SZ} \mathrm{800}$ & 23.75 & - \\
$0.2 \mathrm{M} \mathrm{SZ} \mathrm{900}$ & 29.78 & - \\
0.5 M SZ 600 & 30.87 & - \\
0.5 M SZ 700 & 22.76 & - \\
0.5 M SZ 800 & 24.35 & - \\
0.5 M SZ 900 & 24.76 & - \\
0.8 M SZ 600 & 24.83 & 7,79 \\
0.8 M SZ 700 & 19.67 & - \\
0.8 M SZ 800 & 19.44 & - \\
0.8 M SZ 900 & 24.69 & - \\
\hline
\end{tabular}

The specific surface area of $\mathrm{ZrO}_{2}$ and SZ $0.8 \mathrm{M}$ at $600{ }^{\circ} \mathrm{C}$ also were presented in Table 2. The result showed the specific area of $S Z$ decreased from $\mathrm{ZrO}_{2}$ nanopowder. It caused the sulfate groups loading entered into the pores of

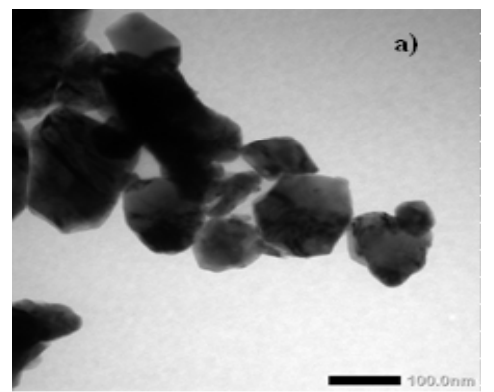

Fig.10. TEM images of: a) $\mathrm{ZrO}_{2}$ b) SZ

\section{CONCLUSION}

Preparation of SZ catalyst obtained the optimal condition of $0.8 \mathrm{M}$ at $600{ }^{\circ} \mathrm{C}$ with the highest acidity value of $3.81 \mathrm{mmol} / \mathrm{g}$ as confirmed by FTIR spectra. The peak of $\mathrm{SO}_{4}{ }^{2-}$ appear at the higher concentration and disappear at higher calcination temperature. The XRD results showed that the SZ crystalline structure was in a monoclinic phase and overall the crystal size decreased with the addition of sulfate. The SAA showed the specific area of SZ
$\mathrm{ZrO}_{2}$ nanopowder at impregnation process. Chen et al., ${ }^{21}$ had also reported that the presence of sulfate at the higher concentration decreased surface area and phase transformation changed from tetragonal to monoclinic phase at the higher calcination temperature. This study showed that nothing changed phase transformation and it was unique from using commercial $\mathrm{ZrO}_{2}$ nanopowder. However, synthesis process also would effect the specific surface area, pore diameter, and pore volume of $\mathrm{SZ}$ catalysts ${ }^{22}$.

\section{TEM characterization}

TEM analysis of $\mathrm{ZrO}_{2}$ and $\mathrm{SZ}$ of 0.8 $\mathrm{M}$ at $600{ }^{\circ} \mathrm{C}$ was shown in Fig. 10 . In this study, TEM analysis showed the presence of particles agglomeration on $\mathrm{SZ}$ of $0.8 \mathrm{M}$ calcined at $600^{\circ} \mathrm{C}$. It could happen because of the heat treatment ${ }^{11}$. The sulfuric acid addition on $\mathrm{ZrO}_{2}$ enhance the dark spots which observed from SZ. It happened because of impregnated sulfate on $\mathrm{ZrO}_{2}$ material which covered and entered to the $\mathrm{ZrO}_{2}$ pores.

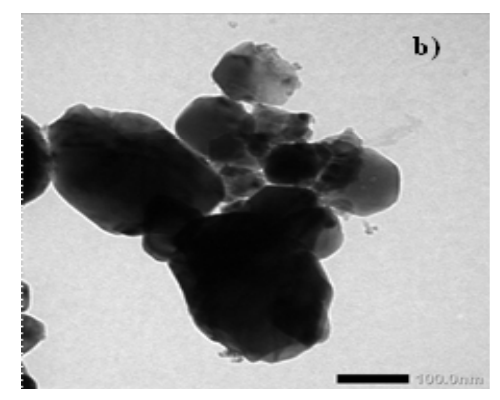

decreased from $\mathrm{ZrO}_{2}$ nanopowder i.e $7.79 \mathrm{~m}^{2} \mathrm{~g}^{-1}$. TEM analysis showed the particles agglomeration on SZ of $0.8 \mathrm{M}$ calcined at $600{ }^{\circ} \mathrm{C}$.

\section{ACKNOWLEDGMENT}

This research was supported by the Indonesia Ministry of Research, Technology, and Higher Education under program of PMDSU Batch II (Contract number: 1979/UN1.P.III/DIT-LIT/ LT/2017).

\section{REFERENCES}

1. Yadav, G. D.; Nair, J. J. Microporous Mesoporous Mater., 1999, 33, 1-48.
2. Kristiani, A.; Corneliasari, K.; Aulia, F.; Abimanyu, H. Energy Procedia., 2015, 65, 8-13. 
3. Fatimah, I.; Rubiyanto, D.; Kartika, N. C. Indones. J. Chem., 2016, 16, 8-13.

4. Omar, W. N. N. W.; Amin, N. A. S. Biomass and Bioenergy., 2011, 35, 1329-1338.

5. Zhai, Y.; Zhang, H.; Hu, J.;Yi, B. J. Memb. Sci. 2006, 280, 148-155.

6. Saravanan, K.; Tyagi, B.; Bajaj, H. C. Applied Catal. B, Environ., 2016, 192, 161-170.

7. Reddy, B. M.; Patil, M. K. Chem. Rev., 2009, 109, 2185-2208.

8. Yu, S.; Jiang, P.; Dong Y.; Zhang, P.; Zhang, Y.; Zhang, W. Bull. Korean Chem. Soc., 2012, 33, 524-528.

9. Li, B.; Gonzalez, R. D. Ind. Eng. Chem. Res. 1996, 35, 3141-3148.

10. Heshmatpour, F.; Aghakhanpour, R. B. Adv. Powder Technol., 2012, 23, 80-87.

11. Said, A. E. A.; El-wahab, M. M. A.; El-aal, M. A. Journal Mol. Catal. A, Chem., 2014, 394, 40-47.

12. Babou, F.; Coudurier, G; Vedrine, J. C. J. Catal. 1995, 152, 341-349.

13. Jin, T.; Yamaguchi, T.; Tanabe, K. J. Phys.
Chem., 1986, 90, 4794-4796.

14. Katada, N.; Endo, J.; Notsu, K.; Yasunobu, N.; Naito, N. J. Phys. Chem., 2000, 104, 10321-10328.

15. Sohn J. R.; Bae, J. H. Korean J. Chem. Eng., 2000, 17, 86-92.

16. Jiang, K.; Tong, D.; Tang, J.; Song, R.; Hu, C. Applied Catal. A, Gen., 2010, 389, 46-51.

17. Utami, M.; Wijaya, K.; Trisunaryanti, W. Key Eng. Mater., 2017, 757, 131-137.

18. Kustov, L. M.; Kazansky, V. B.; Figueras, F.; Tichit, D. J. Catal., 1994, 150, 143-149.

19. Subbarao, E. C.; Maiti, H. S.; Srivastava, K. Pyhs. Stat. Sol., 1974, 21, 9-40.

20. Ejtemaei, M.; Tavakoli, A.; Charchi, N.; Bayati, B.; Babaluo, A. A.; Bayat, Y. Adv. Powder Technol., 2014, 25, 840-846.

21. Chen, F. R.; Coudurier, G.; Joly, J.; Vedrine, J. C. J. Catal., 1993, 143, 616-626.

22. Nayebzadeh, H.; Saghatoleslami, N.; Maskooki, A.; Vahid, B. R. Chem. Biochem. Eng. Q., 2014, 28, 259-265. 